\title{
Role of Biplane double support screw fixation for fracture neck of femur in elderly population
}

\author{
Ahmed El Soudy Hawam ${ }^{1 *}$ MBBCH; Mohamed Ali Elmarghany ${ }^{1}$ MD; Ahmed Ibrahim Akar ${ }^{1}$ MD
}

\author{
*Corresponding Author: \\ Ahmed El Soudy Hawam \\ ahmedhawam1989@gmail.com
}

Received for publication March 21, 2020; Accepted May 11, 2020; Published on line June 03, 2020.

Copyright 2020 The Authors published by Al-Azhar University, Faculty of Medicine, Cairo, Egypt. All rights reserved. This an openaccess article distributed under the legal terms, where it is permissible to download and share the work provided it is properly cited. The work cannot be changed in anyway or used commercially.

doi:

10.21608/aimj.2020.24584.1154

${ }^{1}$ Orthopedic Surgery Department, Faculty of Medicine, Al-Azhar University, Cairo, Egypt

\begin{abstract}
Background: The treatment of fracture of neck femur varies according to the age of the patient, displacement of fracture fragments and duration of the fracture. The aim is to assess the effect of biplane double support screws in fixation of fracture neck of femur in elderly patients.

Patient and Methods: This study was prospective case series study conducted in Al Hussein University Hospital Al Azhar University between January 2019 - January 2020. 20 patients aged more than 50 years with fracture neck of femur were included in the study .Out of the 20 patients 13 were males and 7 were females and they were operated with biplane double support screw fixation method(BDSF) and were followed up for a period of more than 6 months.
\end{abstract}

Results: Out of the 20 patients, 9 patients were excellent, 6 patients were good, 3 patients were fair and 2 patients were poor outcome.

Conclusion: In elderly and in those patients who cannot afford arthroplasty or in those patients where arthroplasty is contraindicated, BDSF method is an alternate method for fixing fracture neck of femur.

Key words: Biplane Double Support Screw fixation, Fracture neck of femur,Harris Hip Score.

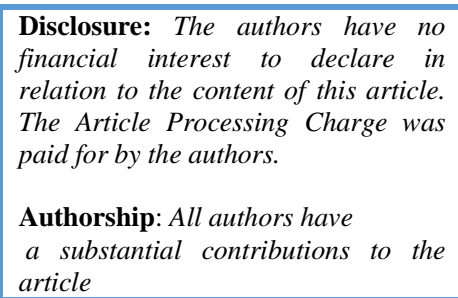

\section{INTRODUCTION}

Fracture of neck of femur is a very common injury in patients more than 50 years of age. According to the present scenario, arthroplasty should be reserved for patients more than 80 years, while in patients age less than 65 sustaining fracture neck of femur, hip preservation should be attempted while the ideal treatment of fracture neck of femur in the age group $60-80$ is still a matter of debate. ${ }^{1}$

A number of controversies exist in relation to the cannulated screw fixation for fracture neck of femur like number of screws to be used, position of screws in the head and neck and the configuration of screws to be used. A number of biomechanical studies have been done in relation to the ideal screw configuration. $^{2-9}$

While some authors have suggested central screw placement ${ }^{10}$, others have suggested peripheral screw placement. ${ }^{2,9-11}$ Some authors believe that the screws should be placed parallel to each other ${ }^{3,4,11-13}$, while others believe that screws should be divergent in lateral view. ${ }^{9-14}$
The most commonly used methods by surgeons worldwide to fix fracture neck of femur is three parallel screws inserted in inverted triangle configuration. ${ }^{15-16}$ This does not always provide appropriate fixation strength. This is especially true if osteoporosis is present, and poor results might subsequently develop. The initial interfragmentary compression of these constructs is frequently insufficient and therefore unable to ensure stability in osteoporotic bone. ${ }^{17}$

Moreover, the constructs could be occasionally instable with regard to varus stresses, anteroposterior bending and torsion because of the screws inserted pretty close to each other with entry points localised in the rather thin section of the cortex near to the greater trochanter, lacking appropriate lateral cortical support. When cannulated screws are used to fix a femoral neck fracture with osteoporosis, intraoperative interfragmentary compression alone may not ensure adequate stability during the healing process because it could soon be lost on fracture impaction. $^{17}$

To overcome this problem of osteoporosis and for those patients in which arthroplasty is contraindicated, Filipov devised a method of Biplane Double Supported Screw Fixation (BDSF) in which the two screws are laid in two planes, which makes it possible for the entry points of middle and distal screws to be placed in distal solid cortex of proximal diaphysis, the distal screw is placed in the dorsal oblique plane while the middle and proximal screws are inserted in ventral oblique plane. BDSF method uses two calcar buttressed screws: The position 
achieved by the distal as well as the middle screw, in view of statics, turns them into a simple beam with an overhanging end, loaded with a vertical force. This beam with an overhanging end successfully supports the head fragment, bearing the body weight and transferring it to the diaphysis. ${ }^{17}$

\section{PATIENTS AND METHODS}

This prospective case series study was carried out in Al Hussein University Hospital Al -Azhar University between January 2019 - January 2020. Twenty patients aged $50-67 \mathrm{yrs}$ with fracture neck of femur were included in the study. Patients $<50$ years and those with old injury $>21$ days are excluded from this study. All patients will be subjected to full clinical examination, plain radiographs evaluation. Thirteen patients were male and seven patient were female (Table 1)

\begin{tabular}{|c|c|c|}
\hline \multicolumn{2}{|c|}{ Variable } & $\begin{array}{c}\text { The studied population } \\
(\mathbf{N = 2 0})\end{array}$ \\
\hline \multicolumn{2}{|c|}{ Age(years) } \\
\multicolumn{2}{|c|}{ Mean $\pm S D$} \\
\multicolumn{2}{|c|}{ Median (range) } & $60.67 \pm 5.83$ \\
\hline \multirow{2}{*}{ Sex } & Male & $13(65 \%)$ \\
\cline { 2 - 3 } & Female & $7(35 \%)$ \\
\hline
\end{tabular}

Table (1): Demographic data of the patients.

\section{Surgical technique}

The patients are put supine on traction table and reduction is done by traction, internal rotation and slight abduction of the limb. A straight incision starting at the base of greater trochanter is made with a length of approximately $7-8 \mathrm{~cm}$ with BDSF method; three cannulated screws are put in two different planes in the lateral view. The distal screw is placed in the dorsal oblique plane while the middle and proximal screws are placed in the ventral oblique plane as shown in (Fig 1).

The first step is to put guide wire for the distal cannulated screw. Its tip is placed $5-7 \mathrm{~cm}$ distally from the base of the greater trochanter in the anterior one-third of the surface of the femoral diaphysis. It is directed proximally at an angle of $150-165^{\circ}$, with inclination from anteriorly-distally to posteriorlyproximally, so that after it touches on the curve of the distal femoral neck cortex, the wire goes into the posterior half of the femoral head as shown in (Fig 2 ). The middle guide wire is placed next. The entry point is at $2-4 \mathrm{~cm}$ proximally from the entry point of the distal wire, in the posterior one-third of femoral shaft.

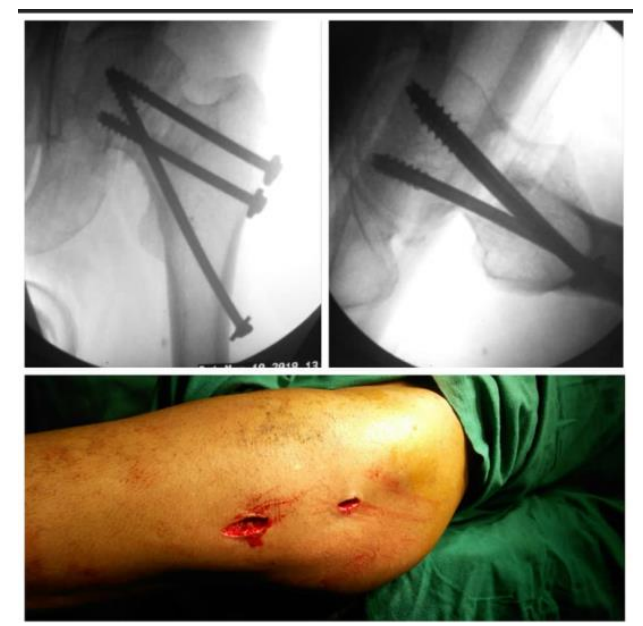

Fig (1): showing positions of screws in AP\&lateal views.

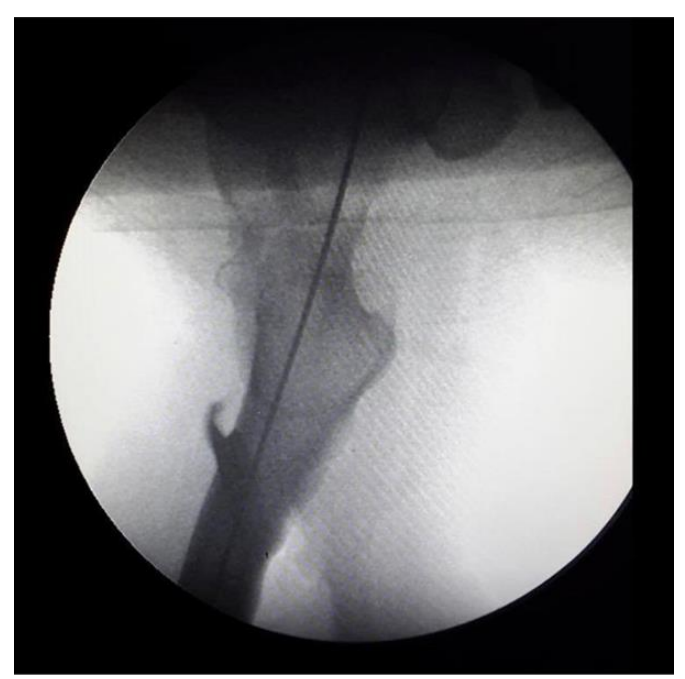

Fig (2): Showing position of first (distal) guidewire in the posterior half of femoral head.

This wire was placed at an angle of $135-140^{\circ}$ and inclined from posteriorly-distally to anteriorlyproximally, so that after it touches the curve of the distal femoral neck cortex, the wire goes into the anterior one-third of the femoral head in the lateral view and in A-P view, the guidewire rests in distal one third of femoral head. The proximal guidewire was laid in the last. The entry point is $1-2 \mathrm{~cm}$ proximally from the entry point of middle wire in the posterior one-third of femoral shaft. It was placed parallel to the middle wire and is directed posteriordistally to anterior proximally so that in the A-P view, the guidewire lies in proximal one-third of femoral head and in the lateral view, it lies in anterior one-third of femoral head as shown in (Figures $\underline{3}$ a and $\underline{b}$ ) 

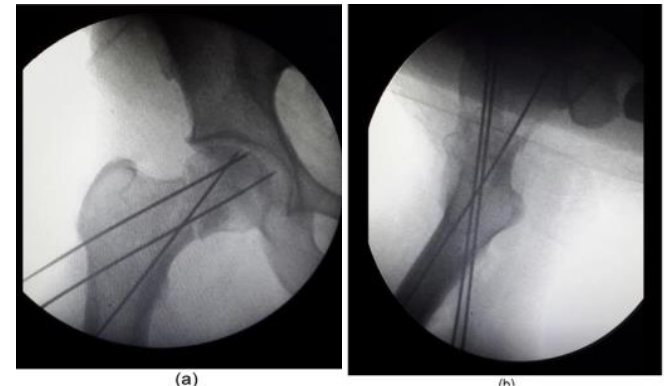

Fig (3): a) Showing final position of guidewires in the AP view. b) Showing final position of guidewires in lateral view.

Being perpendicular to fracture surface, the middle and proximal screws are placed first followed by insertion of the distal screw as shown in (Figures $\underline{4}$ a and $\underline{b})$.

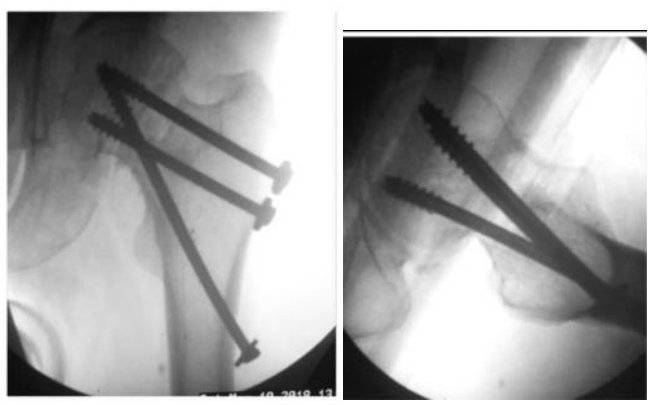

Fig (4): a) Showing final position of screws in the AP view b) Showing final position of screws in lateral view

\section{Post-operative protocol:}

Postoperative radiographs were obtained on the first postoperative day. The patient was encouraged to do static quadriceps and active assisted/active Straight Leg Raising (SLR) exercises once the patient feels comfortable. The patient was made to sit up on the bedside and non-weight bearing. Walking was started 24 hours after the surgery on the normal side. Patients were discharged from hospital 48 to 72 hours after surgery. All the patients were followed up clinically and radiologically after three weeks, six weeks, three months, six months, twelve months and after two years. Partial weight bearing was allowed after three weeks and full weight bearing was allowed after the radiographic union was evident. Radiologically fracture union was defined as continuity of at least three cortices in AP and lateral views without any fracture gap. Clinically fracture was considered as healed when there was no local tenderness and patient could do full weightbearing without any support.

\section{RESULTS}

The study included 20 patients with fracture neck of femur treated by internal fixation using the novel method Biplane Double Supported Screw Fixation
(BDSF). All patients were evaluated using Haris Hip score that was used for evaluation of the functional outcome of our patients, 9 patients were excellent, 6 patients were good, 3 patients were fair, 2 patients were poor as in table 2 .

\begin{tabular}{|c|c|}
\hline & $\begin{array}{c}\text { The studied population } \\
(\mathbf{N = 2 0})\end{array}$ \\
\hline Excellent & $9(45 \%)$ \\
\hline Good & $6(30 \%)$ \\
\hline Fair & $3(15 \%)$ \\
\hline Poor & $2(10 \%)$ \\
\hline
\end{tabular}

Table (2): Functional Outcome of the studied patients

\section{DISCUSSION}

The new method of Biplane double-supported screw fixation (BDSF) increases the fixation strength by its innovative concept of biplane positioning of the three screws, which makes it possible for the screws to be placed at an increased angle, so they lean on two solid supporting points. ${ }^{17}$

The position of the distal screw as well as the middle screw achieved by the method, in terms of statics, turns them into a simple beam with an overhanging end, loaded with a vertical force. This beam with an overhanging end successfully supports the head fragment bearing the body weight and transferring it to the diaphysis. Moreover, due to the biplane placement, enough space for a third screw is provided, whereas in the conventional methods for fixing neck femur, only one or a maximum of two screws can be placed at an obtuse angle. ${ }^{18}$

Regarding demographic characteristics, the age of the patients ranges from 51 to 72 years, $65 \%$ of patients were males, and in accordance with our results, the study of Kalia et al. ${ }^{19}$ that aimed to study the role of Biplane Double Supported Screw Fixation For Fracture Neck of Femur In Elderly Population, and reported that Out of the 25 patients, 17 were males $(68 \%)$ and $8(32 \%)$ were females. The average age was 67.8 years. The youngest patients were aged 52 years while eldest being 88 years. Majority of the patient (18 out of 25) belong to 60-80 years of age group. ${ }^{19}$

A retrospective study of Filipov et al. ${ }^{17}$ that aimed to evaluate the clinical outcomes from the first 5-year period of patient's treatment with the novel BDSF method for femoral neck fracture fixation the subjected patients comprised 42 males $(20.28 \%)$ and 165 females $(79.71 \%$ ), aged $75.7 \pm 10.3$ (range 49 99) and $76.4 \pm 9.8$ (range 38-93) years, respectively, with no significant age difference between the genders $(\mathrm{P}=0.56) .{ }^{17}$ 
There seems to be a lot of controversy regarding the cannulated screw fixation for fracture neck femur like the number of screws to be used, configuration of screws and their position in head and neck. The method most widely practiced by surgeons for fixing the fracture neck femur is by three cancellous screws placed parallel to each other and various authors have reported the failure rate to be as high as $20-42 \%{ }^{20}$

\section{CONCLUSION}

BDSF method was devised mainly to address that group of patients who have contraindications for arthroplasty and we have found this as an excellent method in terms of fracture consolidation and functional outcome. By providing additional cortical support, the novel BDSF method enhances femoral neck fracture fixation strength, reveals excellent clinical outcomes and is a valid alternative to other treatment methods.

\section{REFERENCES}

1. Burgers,Van Geene and Van Bekerom, et al Total hip arthroplasty versushemiarthroplasty for displaced femoral neck fractures in the healthy elderly: a meta-analysis and systematic review of randomized trials. International Orthopaedics (SICOT). 2012; 36:1549-60.

2. Filipov and B.Gueorguiev. Unique stability of femoral neck fractures treated with the novel biplane double-supported screw fixation method: A biomechanical cadaver study. El Sevier. 2015; 46:218-26.

3. JJ Yang, LC Lin and $\mathrm{KH}$ Chao, et al. Risk Factors for Nonunion in Patients with Intracapsular Femoral Neck Fractures Treated with Three Cannulated Screws Placed in Either a Triangle or an Inverted Triangle Configuration. The Journal of Bone \& Joint Surgery. 2013; 95:61-69.

4. Ye Ye, J Hao and C Mauffrey, et al. Optimizing Stability in Femoral Neck Fracture Fixation. Orthopedics 2015; 38(10):625-30.

5. M panteli, P Rodham and PV Giannoudis. Biomechanical rationale for implant choices in femoral neck fracture fixation in the nonelderly. El Sevier 2015; 46, 445-52.

6. Rupprecht M, Grossterlinden L, Sellenschloh K. et al. Internal fixation of femoral neck fractures with posterior comminution. International Orthopaedics (SICOT). 2011; 35:1695-1701.

7. Florschutz, Anthony V, Langford, et al. Femoral Neck Fractures Current management. Journal of Orthopaedic Trauma. 2015; 29: 121-12.

8. Y Zhang, L Tian, Y Yan, et al. Biomechanical evaluation of the expansive cannulated screw for fixation of femoral neck fractures. El Sevier. 2011; 42: 1372-76.

9. M Butler, ML Forte, SB Joglekar, et al. Evidence Summary: Systematic Review of Surgical Treatments for Geriatric Hip Fractures. The Journal of Bone \& Joint Surgery. 2011; 93:1104-15.

10. BR Satish, AV Ranganadham, et al. Four quadrant parallel peripheral screw fixation for displaced femoral neck fractures in elderly patients. Indian J Orthop. 2013; 47(2):174-81.

11. P Londhe, HJ Mangukiya, B Agrawal, et al. Comparison of radiological and functional outcome in patients with femoral neck fracture operated with dynamic hip screw versus multiple cannulated screws. International Journal of Orthopaedics Sciences. 2018; 4(2): 1040-48.

12. O Filipov. The method of biplane doublesuppoted screw fixation (BDSF) at femoral neck fractures - principles and clinical outcomes. Journal of IMAB - Annual Proceeding (Scientific Papers). 2013; 19:423-28.

13. Murphy D K, Randell T, Brennan K L, et al. Treatment and Displacement Affect the Reoperation Rate for Femoral Neck Fracture. Clin Orthop Relat Res. 2013; 471: 2691-2702 .

14. $\mathrm{R}$ Thein, A Herman, $\mathrm{P}$ Kedem, et al. Osteosynthesis of Unstable Intracapsular Femoral Neck Fracture by Dynamic Locking Plate or Screw Fixation: Early Results. Journal of Orthopaedic Trauma. 2014; 28:70-76.

15. Mathivanan P, Prabu GR and Srinivasan A. Case series of four quadrant parallel peripheral screw fixations for fractured neck of femur and their outcome. J. Evolution Med. Dent. Sci 2017; 6(44):3404-10.

16. Huang HK, Su YP, Chen CM, et al. Displaced femoral neck fractures in young adults treated with closed reduction and internal fixation. Orthopedics. 2010; 33(12):873.

17. Filipov O. Biplane double-supported screw fixation (F-technique): A method of screw fixation at osteoporotic fractures of the femoral neck. Eur J Orthop Surg Traumatol. 2011; 21(7):539-43.

18. JE Gjertsen, T Vinje, LB Engesaeter, et al. Internal Screw Fixation Compared with Bipolar Hemiarthroplasty for Treatment of Displaced Femoral Neck Fractures in Elderly Patients. The Journal of Bone \& Joint Surgery. 2010; 92:61928.

19. A Kalia, J Singh and N Ali. Role of Biplane Double Supported Screw Fixation For Fracture Neck Femur In Elderly Population: A Prospective Study. The Open Orthopaedics Journal. 2018; 12:514-24.

20. S Moerman, NMC Mathijssen, WE Tuinebreijer, et al. Hemiarthroplasty and total hip arthroplasty in 30,830 patients with hip fractures: data from the Dutch Arthroplasty Register on revision and risk factors for revision. Acta Orthopaedica. 2018; 89(5):50914. 